\title{
O CONSUMO DE ALIMENTOS ULTRAPROCESSADOS E SUA DIVULGAÇÃO, INCLUINDO PUBLICIDADE DIRECIONADA À CRIANÇA: DIREITO BRASILEIRO E DIREITO INTERNACIONAL
}

\author{
Oscar Ivan Prux ${ }^{1}$ \\ Marina Weiss Gonçalves ${ }^{2}$
}

\begin{abstract}
RESUMO: O presente artigo examina questões relacionadas ao mercado de alimentos ultraprocessados cujo direcionamento visa o consumo primordialmente por parte de crianças, considerando sua hipervulnerabilidade, seus direitos fundamentais e da personalidade envolvidos. Destaca a questão da oferta desses alimentos (publicidade explícita e implícita), seu consumo pelos menores e consequências das relações de consumo dessa ordem. Sem olvidar legislação internacional à qual faz referência, em nível nacional o trabalho fundamenta-se no conteúdo do sistema de proteção ao consumidor (Lei $n^{\circ}$ 8.078/90, Lei ${ }^{\circ}$ 8.069/90 e normas regulamentares). Baseia-se, para tanto, em pesquisas bibliográficas e valese do método hipotético dedutivo para confecção.
\end{abstract}

Palavras-chave: Crianças; Alimentos ultraprocessados; Publicidade; Direitos da personalidade; Direitos fundamentais.

\section{CONSUMPTION OF ULTRAPROCESSED FOOD AND ITS DISSEMINATION, INCLUDING ADVERTISING DIRECTED TO CHILDREN: BRAZILIAN LAW AND INTERNATIONAL LAW}

\begin{abstract}
This article examines issues related to ultra-processed food market, which aimed primarily at consumption by children, considering their hypervulnerability, their fundamental rights and their personality rights. It highlights the issue of the offer of these foods (explicit and implicit advertising), their consumption by minors and consequences of consumption relationships of this order. Without forgetting the international legislation to which it refers, at the national level the work is based on the content of the consumer protection system (Law $n^{\circ} 8.078 / 90$, Law $n^{\circ} 8.069 / 90$ and regulatory norms). Therefore, is based on bibliographical research and uses the hypothetical-deductive method for its preparation.
\end{abstract}

Key-words: Kids; Ultra-processed food; Advertising; Hypervulnerability; Personality rights; Fundamental rights.

\footnotetext{
${ }^{1}$ Pós-Doutor pela FDUL. Doutor em Direito das Relações Sociais pela PUCPSP. Mestre em Direito das Relações Sociais pela UEL. Com licenciatura em pedagogia pela FACIBRA. Graduado em Direito pela UEL. Graduado em Ciências Econômicas pela Fundação Faculdade Estadual de Ciências Econômicas de Apucarana. Atualmente é professor do curso de mestrado em Ciências Jurídicas da UniCesumar. Tem experiência na área de Direito, atuando principalmente nos seguintes temas: direito do consumidor; direito da concorrência, direito civil, direito empresarial e direitos da personalidade. Endereço postal: Rua Oswaldo Cruz, n ${ }^{\circ}$ 763, Centro, Apucarana/PR, CEP 86.800720. E-mail: prux@uol.com.br

${ }^{2}$ Mestranda em Ciências Jurídicas pela UniCesumar. Especialista em Direito do Consumidor pelo Damásio Educacional. Especialista em Direito Civil pela PUCPR. Graduada em Direito pela PUCPR. Endereço postal: Rua Zeferino Sanches Parra, $\mathrm{n}^{\circ}$ 300, Jardim Itália, Marialva/PR, CEP 86.990-000. E-mail: marinaweissgo@gmail.com
} 


\section{INTRODUÇÃO}

A sociedade de consumo de massa em que estamos inseridos caracteriza-se, principalmente, pela ampla utilização da publicidade como forma de estimular o consumidor a consumir além de suas necessidades, aderindo ao simples desejo de compra e consumo de produtos e serviços. A indução para essa escolha através da publicidade deve ser visualizada em sentido amplo, envolvendo todas as manifestações do fornecedor que provoquem o desejo de celebrar a relação de consumo e consumir. Nesse sentido, os fornecedores de gêneros alimentícios (fabricantes e comerciantes), como forma de incrementar seus negócios, têm se valido intensamente da publicidade de alimentos ultraprocessados. Entretanto, em especial quando envolve o público infantil, o consumo desse tipo de alimento projeta um contexto problemático, na medida em que suas fórmulas são ricas em açúcares, sais e gorduras e, portanto, não conformes com uma dieta saudável, considerado o risco à saúde que implicam, direito naturalmente fundamental para a vida com qualidade das crianças. É com base nesse cenário que o presente artigo tratará da conjuntura instaurada na sociedade no que se refere a essa área, com especial destaque para os direitos básicos do consumidor, para a publicidade e para o papel que ela desempenha no incentivo ao consumo de gêneros alimentícios que não primam por conter em suas características a qualidade de serem saudáveis na melhor acepção do termo. O trabalho vale-se do método hipotético dedutivo e, com base nas pesquisas bibliográficas, são abordados e analisados aspectos da legislação, doutrina e jurisprudência, tudo com o sentido maior de proteção das crianças, sua dignidade humana, seus direitos fundamentais e seus direitos da personalidade.

\section{AS CONDIÇÕES SOCIAIS E O SENTIDO AMPLO DE PUBLICIDADE}

A Lei $n^{\circ}$ 8.078/90 incorporou a concepção de que o consumidor pode ser atingido em duas esferas: sua incolumidade físico-psíquica (devido ao defeito do produto) ou sua incolumidade econômica/patrimonial (devido ao vício do produto), sendo que estas não se excluem, tornando-se comum as situações em que se somam. Por isso, as proteções devem estar em conformidade com as necessidades extraídas da realidade social, podendo-se mencionar que o consumo de alimentos ultraprocessados está associado ao desenvolvimento de diversas doenças/patologias, conforme se demonstrará adiante, o que significa dizer que seu consumo implica em riscos à saúde, à integridade físico-psíquica e, em essência, à vida do 
consumidor.

Observe-se que normalmente as crianças não possuem renda, mas são agentes importantes nas escolhas sobre produtos e serviços comprados pela família, principalmente quanto aqueles que lhes interessa consumir. E por conta disso, as empresas fornecedoras dão especial atenção para esse público-alvo que costuma representar fator decisivo para suas vendas e consequentes lucros; e dar especial atenção significa comunicar-se com esse segmento mediante as diversas formas de oferta e publicidade (marketing, neuromarketing, etc.) para que iniciativas dos menores convençam os adultos detentores da renda a, sem priorizar aspectos quanto aos alimentos serem efetivamente saudáveis, comprar produtos ultraprocessados.

Quando se fala em um sentido amplo para a divulgação, a oferta e mesmo para a publicidade, se está a referir à todas as formas de transferências de conteúdos (palavras, sons, aromas, símbolos, signos, imagens ou outros meios) que induzam para a aquisição e/ou consumo de determinado produto - no caso sob exame, de alimentos ultraprocessados. As situações mais corriqueiras costumam ser de publicidade que pode ser considerada enganosa por comissão ou omissão, já que elementos prejudiciais à saúde contidos no produto não são informados ao consumidor. Ou mesmo, a comunicação publicitária acaba classificada como abusiva por induzir o consumidor a se comportar de maneira prejudicial à sua saúde. Trata-se de um panorama que vai além e abrange todas as formas de comunicação (visual, auditiva, etc.). São exemplos dessa ordem, não apenas a publicidade explícita, mas desde o layout da embalagem até a visão de um "influencer" ou "youtuber" que pode estar apenas comendo o alimento e dessa forma induzindo o consumidor infantil a adquirir/consumir o produto.

Assim, considerando que a criança, ser em desenvolvimento, possui uma condição de vulnerabilidade agravada, na medida em que é guiada principalmente pelo paladar, aroma e demais detalhes da aparência do produto, não acolhe uma decisão consciente e sim é influenciada pela comunicação do fornecedor. De outro lado, os adultos ou desconhecem os riscos a que submetem os menores quando lhes dão acesso ao consumo de alimentos ultraprocessados, ou simplesmente desejam agradá-los, muito embora desconsiderando aspectos ligados à saúde. Essa realidade tem sido comum no Brasil e vem influenciando o cotidiano das pessoas. Nas últimas décadas, em paralelo ao aumento da variedade e 
quantidade de produtos ultraprocessados, vem sendo constatado o fenômeno da obesidade atingindo muitas crianças (CHANG; et al, 2021). ${ }^{3}$

Importante atentar para o quanto as formas de oferta, em específico de publicidade, influenciam nessa problemática, de modo que o direito não deve ficar alheio e via legislação, incluindo a regulatória, busque contribuir para o desiderato de proteção dos consumidores, principalmente os hipervulneráveis - no caso, as crianças, que não possuem ciência de que estão frequente e reiteradamente consumindo produtos que lhes fazem mal à saúde. Tal proteção deve principiar não apenas nas questões de fabricação (a fórmula ser de alimento saudável), mas dar especial atenção às formas de divulgação dos produtos ultraprocessados, posto que a divulgação, principalmente através da publicidade, é o vetor maior desse desvirtuamento que vem afetando a saúde de tantas pessoas, principalmente as crianças em sua condição de hipervulneráveis.

\section{A PUBLICIDADE ABUSIVA DESTINADA AO PÚBLICO INFANTIL, FRENTE À SUA VULNERABILIDADE AGRAVADA}

Existem muitas formas de divulgar um produto: mostrar sua imagem; impregnar o ar com seu aroma agradável (mesmo que artificial); utilizar aparência atraente, etc. Por isso, os fornecedores costumam dar atenção a cada detalhe da embalagem, da rotulagem, da publicidade e outras formas pelas quais o produto é visto pelo consumidor. No tocante a rotulagem, a Resolução de Diretoria Colegiada $n^{\circ}$ 429/2020 da Agência Nacional de Vigilância Sanitária buscou consagrar o direito básico à informação do consumidor. Estabeleceu disposições sobre a rotulagem de alimentos e impôs a rotulagem nutricional frontal em alimentos cujos índices de nutrientes críticos ultrapassem os limites estabelecidos na legislação específica (Instrução Normativa $n^{\circ}$ 75/2020). Entretanto, verifica-se que diante da publicidade e da influência que ela exerce sobre as crianças, a informação que traduz os elementos para se classificar um produto como não saudável costuma não ser suficiente para afastar e diminuir o volume de seu consumo. Há na criança um desejo de consumir esses alimentos, seja pela aparência deles, seja pelo poder de persuasão utilizado sutilmente pelo fornecedor. Considerado os efeitos desse tipo de consumo, medidas precisam ser adotadas para que as crianças não sejam prejudicadas em sua saúde, sabendo-se, inclusive, que as consequências desse tipo de consumo durante a infância se protrairão pelo restante da vida da

\footnotetext{
${ }^{3}$ Crianças que comem muitos alimentos ultraprocessados tendem a ser adultos obesos e mais suscetíveis a sofrer com inúmeras patologias.
} 
pessoa. Por isso, a proteção do consumidor, de raiz constitucional, demonstra-se importante norma de ordem pública e interesse social.

As práticas empresariais (fabricação e comercialização) são complexas e mutáveis sucessivamente. No século em que vivemos, as práticas de comercialização podem ser classificadas como a face pós-produção da sociedade de consumo e envolvem tanto a circulação de bens até o consumidor, quanto as situações que ocorrem no pós-venda que guardam relação com referida movimentação. Entre as diversas formas de práticas comerciais, destaca-se o marketing, conceito de difícil definição, mas relacionado a mecanismos de fomento de vendas, sendo um exercício profissional essencial à existência do mercado de consumo, que busca purificá-lo (HERMAN BENJAMIN, 1991, p. 134-145). Uma de suas faces é a publicidade, definida como símbolo próprio e verdadeiro da sociedade moderna (ALPA, 1986, p. 123). Note-se que a publicidade não é um dever legal imposto ao fornecedor: é um direito exercitável à sua conta e risco que deve observar a principiologia do Código de Defesa do Consumidor (HERMAN BENJAMIN, 1991, p. 165).

A visão moderna do contrato visualiza o negócio jurídico como um processo que assegura a tutela do consumidor, não somente na fase contratual, mas também nas fases précontratual e pós-contratual. Nesse contexto, a publicidade desempenha papel especial durante a fase pré-contratual, na medida em que busca a aproximação entre o consumidor e o produto/serviço. Ou seja, está intimamente relacionada à oferta, sendo possível afirmar que a publicidade exerce "poderosa ação sobre o consumidor, capaz de criar-lhe necessidades, mexer com o seu inconsciente, modificar padrões de consumo, inserindo o produto anunciado entre as novas necessidades" (CAVALIERI FILHO, 2014, p. 139-140). Por isso, a regulação da publicidade deve reger-se por alguns princípios, dentre os quais, destacam-se: o princípio da identificação (art. 36, caput, CDC), que determina que a publicidade deve ser fácil e imediatamente identificada como tal; o princípio da vinculação contratual (arts. 30 e 35, CDC), que afirma que a publicidade deve ser suficientemente precisa obrigando ao fornecedor que a fizer veicular e integrando o contrato que vier a ser celebrado; o princípio da inversão do ônus da prova (art. 38, CDC), que determina que a veracidade e a correção da comunicação publicitária cabem a quem a patrocina. Quanto ao tema aqui explanado, o princípio da transparência da fundamentação da publicidade (art. 36, parágrafo único, CDC) e o princípio da veracidade da publicidade (art. $37, \S 1^{\circ}, \mathrm{CDC}$ ) desempenham papel fundamental.

O princípio da transparência sinaliza compulsoriamente que a publicidade deverá ser 
fundamentada em dados fáticos, técnicos e científicos, possibilitando que a relação contratual com o consumidor seja menos danosa, através do fornecimento de informações corretas e adequadas sobre os produtos e serviços que lhes são oferecidos (CAVALIEIR FILHO, 2014, p. 144). Aqui, possível afirmar que o princípio da transparência é forma de efetivar o direito básico à informação do consumidor (art. $6^{\circ}$, III, CDC). Na prática, cabe ao fornecedor a transmissão de informações substanciais ao consumidor, para que este possa exercer de modo consciente seu direito de escolha no momento da compra. O princípio da veracidade contido no art. 37 do CDC veda toda e qualquer forma de publicidade enganosa ou abusiva. Nesse sentido, o $\S 1^{\circ}$ do referido dispositivo ao tratar da publicidade enganosa a conceitua como aquela informação ou comunicação, parcial ou totalmente falsa (até mesmo por omissão), que induz o consumidor em erro a respeito da natureza, características, qualidade, quantidade, propriedades, origem, preço e quaisquer outros dados sobre produtos e serviços. Refira-se, ainda, que o $\$ 2^{\circ}$ do art. 37 , quando trata da publicidade abusiva, fixa o princípio da nãoabusividade da publicidade. Abusiva é a publicidade que realiza qualquer forma de discriminação, que explora o medo ou a superstição, que se aproveita da deficiência de julgamento e experiência da criança, que desrespeita valores ambientais, ou que é capaz de induzir o consumidor a se comportar de forma prejudicial ou perigosa à sua saúde ou segurança.

No tocante à publicidade enganosa, fica explícito que para sua caracterização basta a mera enganosidade potencial, ou seja, a capacidade de indução ao erro e, nesse sentido, alegações ambíguas ou parcialmente verdadeiras também a caracterizam. Outro detalhe: o silêncio e até mesmo alegações literalmente verdadeiras podem ser enganosos quando induzem o consumidor (homem médio) a entendimentos equivocados. Inclusive, o standard da enganosidade varia de acordo com a categoria de consumidor. Assim, em sede de responsabilidade civil, não se exige a intenção culposa de enganar - ou seja, a responsabilidade é objetiva, sendo irrelevante a boa ou má-fé do anunciante, nem mesmo é necessário o erro real, bastando o erro potencial (HERMAN BENJAMIN, 1991, p. 193-197). A publicidade enganosa, portanto, tem como núcleo a essencialidade da informação. É enganosa a ação comissiva ou omissiva que influi na decisão do consumidor, sempre que deixa de fornecer, ou fornece de forma insuficiente ou distorcida, dados essenciais sobre as características, qualidades ou quantidades do produto - enfim, qualquer informação capaz de induzir o consumidor em erro, pois se detivesse as informações corretas, sua decisão de adquirir o produto/serviço poderia não ocorrer ou ocorreria de modo diverso (CAVALIERI 
FILHO, 2014, p. 146). Ao vedar a publicidade enganosa, o CDC busca "proteger a confiança do consumidor frente à promoção da atividade publicitária pelo fornecedor" (MIRAGEM, 2019, p. 357). Acrescente-se que a publicidade abusiva ( $\$ 2^{\circ}$ do art. 37) apresenta rol apenas exemplificativo, porto que por diversas formas pode carrear a ideia de exploração ou opressão do consumidor e a violação de valores caros à sociedade de consumo (HERMAN BENAJMIN, 1991, p. 207-208). Nestas situações, tem-se o abuso de direito que viola normas legais, princípios jurídicos e valores sociais ou juridicamente apreciados, cabendo verificação do conceito jurídico indeterminado no caso concreto. Bruno Miragem (2019, p. 361) ressalta que os efeitos da publicidade abusiva alcançam toda a sociedade e, portanto, detêm caráter difuso (cabendo a tutela coletiva).

Naquilo que é essencial para o presente trabalho, frise-se que já faz mais de uma década que diversos países desenvolvidos passaram a regular a publicidade direcionada à criança, incluindo-se em específico a de alimentos ultraprocessados (CHANG; et al, 2021). O Brasil, embora reconheça o princípio da hipervulnerabilidade da criança em razão de sua deficiência de julgamento e inexperiência em relação ao mundo exterior, incluindo suas qualidades naturais de pessoa em desenvolvimento (MIRAGEM, 2019, p. 366), demonstra dificuldades nessa área.

A Constituição Federal, em seu art. art. 220, $\S 3^{\circ}$, II determina que compete à lei federal estabelecer meios legais que garantam à pessoa e à família a possibilidade de se defenderem da propaganda de produtos, práticas e serviços que possam ser nocivos à saúde (ressalte-se a imprecisão técnica na redação do artigo, que denomina de propaganda o que em verdade é publicidade). Já o caput do art. 227 da Carta Magna determina que é dever da família, da sociedade e do Estado assegurar à criança, com absoluta prioridade, o direito à vida, à saúde, à alimentação, à educação, à dignidade, ao respeito, além de colocá-la a salvo de toda forma de negligência, discriminação, exploração, violência, crueldade e opressão. Consagra-se, pois, o princípio da prioridade do interesse da criança. O CDC, além de elencar a publicidade abusiva em seu art. $37, \S 2^{\circ}$, estabelece em seu art. 39, IV que também será abusiva a publicidade que se prevalecer da fraqueza ou ignorância do consumidor, tendo em vista sua idade, saúde, conhecimento ou condição social, para impingir-lhe o consumo de seus produtos ou serviços. Ainda como parte dos microssistemas de proteção aos mais vulneráveis, a Lei ${ }^{\circ}$ 8.069, de 13 de julho de 1990, denominada Estatuto da Criança e do Adolescente, dispõe em seus artigos $3^{\circ}$ e $4^{\circ}$ que a criança goza de todos os direitos inerentes à pessoa humana, com proteção integral, assegurado seu pleno desenvolvimento físico, mental, moral, 
espiritual e social, sendo imposto à família, à sociedade e ao Poder Público a efetivação, dentre outros, de seu direito à vida, à saúde e à alimentação.

Note-se que no Brasil existe uma auto-regulamentação publicitária (denominada de Código Brasileiro de Auto-Regulamentação Publicitária), regramento dito ético aplicado pelo Conselho Nacional de Auto-Regulamentação Publicitária (CONAR). Na norma, mais especificamente em sua Seção 11, art. 37, I e II, existe a determinação de que a publicidade dirigida ao público infantil deverá refletir cuidados especiais quanto à segurança e às boas maneiras e não poderá, dentre outras proibições, desmerecer valores sociais positivos, impor a noção de que o consumo de determinado produto/serviço proporciona superioridade ou inferioridade, provocar situações de constrangimento aos pais ou responsáveis com propósito de impingir consumo, empregar crianças como modelos para vocalizar apelo direto, bem como deverão respeitar a dignidade, a ingenuidade, a credulidade, a inexperiência e o sentimento de lealdade do público-alvo, dando atenção especial às suas características psicológicas, inclusive, presumidamente, sua menor capacidade de discernimento, tudo obedecendo a cuidados tais que evitem eventuais distorções psicológicas. Ainda, nos incisos III e IV, recrimina as ações de merchandising que empreguem crianças, elementos lúdicos do universo infantil ou artifícios que possuam a finalidade de captar sua atenção. Outro detalhe: muito embora claramente insuficiente e inapropriado (pois a publicidade direcionada para esses menores deveria ser radicalmente proibida), determina que a publicidade dirigida às crianças fica restrita aos intervalos e espaços comerciais. Cumpre destacar que o Conselho Nacional dos Direitos da Criança e do Adolescente (CONANDA) aprovou a Resolução $n^{\circ}$ 163, de 13 de março de 2014, cujos artigos $1^{\circ}$ e $2^{\circ}$ tratam e definem a abusividade do direcionamento de publicidade e de comunicação mercadológica à criança. Os dispositivos definem que a abusividade ocorre quando há intenção de persuadi-la ao consumo de qualquer produto/serviço, especialmente através da utilização de linguagem infantil, efeitos especiais, excessos de cores, personagens ou apresentadores infantis, desenhos animados ou animações, bonecos e similares e, inclusive, de promoções com distribuição de prêmios ou brindes colecionáveis, ou qualquer outro tipo de apelo ao público infantil. No mesmo sentido, o Enunciado $\mathrm{n}^{\circ} 4$ do Instituto Brasileiro de Política e Direito do Consumidor afirma que a criança, para os efeitos do Código de Defesa do Consumidor, é considerada hipervulnerável perante a publicidade e a comunicação mercadológicas a ela dirigida, devendo ser protegida de maneira especial. 
Importante analisar o tratamento da publicidade destinada ao público infantil no âmbito internacional. Para tanto, passa-se à análise de alguns aspectos relacionados à publicidade em ordenamentos estrangeiros.

\section{A CONSCIÊNCIA DO RESULTADO DO CONSUMO DE ALIMENTOS ULTRAPROCESSADOS E A REGULAÇÃO DA PUBLICIDADE DIRECIONADA AO PÚBLICO INFANTIL NO DIREITO INTERNACIONAL}

No panorama internacional, países desenvolvidos realizaram pesquisas envolvendo o resultado do consumo de alimentos ultraprocessados por adultos e crianças. Em relação a estas, se tornaram frequentes as aprovações de normas, principalmente quanto à publicidade desse tipo de alimento. Na Alemanha, a Lei da Proteção da Juventude e Tratado Estadual de Proteção à Mídia Juvenil (Jugendschutzgesetz und jugendmedienschutz-staatsvertrag der lander, p. 89) determina que a publicidade dirigida à criança não pode causar danos físicos ou mentais, não pode mostrar crianças em situações perigosas, não pode conter chamadas diretas de compra e não pode aproveitar-se da inexperiência e credulidade dos menores ou solicitar que estes persuadam seus pais, responsáveis ou terceiros a adquirir os produtos e serviços ofertados. O Canadá, através do "Canadian Code of Advertising Standards", determina que a publicidade não pode explorar a credulidade, a falta de experiência e o senso de lealdade das crianças e não deve apresentar informações ou ilustrações que possam resultar em danos físicos, emocionais ou morais.

Por sua vez, a Dinamarca também reconhece que as crianças são vulneráveis à publicidade, pois são mais influenciáveis e se impressionam com maior facilidade. $\mathrm{O}$ "Marketing Practices Act" determina que a publicidade não poderá ser contrária aos costumes, à decência, à saúde e à segurança, além de incluir entre as práticas comerciais agressivas aquelas que estimulem a criança a comprar o produto/serviço ou a persuadir seus pais ou responsáveis a comprá-lo. Em Portugal, o Código de Publicidade (Decreto Lei ${ }^{\circ}$ 330/90) determina em seu artigo 25 que programas para crianças cuja duração não exceda 30 (trinta) minutos não podem ser interrompidos por publicidade. Na Espanha, a Lei n 34/1988 considera ilícita a publicidade dirigida à criança quando busca manipular sua inexperiência ou credulidade, bem como quando induz o menor a persuadir pais ou responsáveis para que efetivem à compra. A publicidade não deve, segundo a norma, apresentar crianças em situações perigosas nem induzir a erro sobre as características do produto ou sobre as aptidões necessárias para que a criança o utilize sem causar danos a si ou a terceiros. Essas disposições 
são muito pertinentes quando se trata da divulgação de produtos ultraprocessados que acabam com sua imagem manipulada, como se fossem saudáveis - o que não é verdade.

$\mathrm{Na}$ Inglaterra, determina o "Generic Code of Practice on Television Advertising Standards" (2013. p. 31) que a publicidade não pode levar a criança a crer que o consumo de determinado produto lhe conferirá superioridade ou inferioridade. A disposição legal refere, ainda, que anúncios de produtos que não sejam adequados para as crianças não podem ser exibidos durante ou próximos de programas voltados para elas. Já a Irlanda possui um código destinado exclusivamente à proteção da criança frente à publicidade, norma que é denominada de "Children's Advertising Code", dentro do "Advertising Standards Autorithy for Ireland". O código define como criança todos os menores de 18 (dezoito) anos, determina que a comunicação mercadológica deve levar em consideração que os mesmos carecem de conhecimento, experiência e maturidade de julgamento e reconhece que a responsabilidade primária compete aos pais e responsáveis. Além disso, afirma que as crianças percebem, reagem e são influenciadas pelas comunicações de marketing de acordo com o contexto em que a mensagem é transmitida. Na Holanda, o "Dutch Advertising Code" (2011, p. 91-92) proíbe que a publicidade de alimentos seja dirigida a menores de 7 (sete) anos, exceto quando produzida em cooperação com o governo e/ou outras autoridades da área da nutrição, saúde e de exercícios físicos. Na Noruega, o Conselho de Consumidores questionou a qualidade nutricional dos purês de frutas comercializados para crianças de até 12 (doze) meses de idade, que prometiam alimentação rápida e saudável. O Conselho considerou a venda antiética, além de enganosa, pois induzia os pais e responsáveis ao engano, já que o produto continha elevados índices de açúcar - um pacote do purê oferecia mais açúcar do que a recomendação máxima diária para crianças pequenas (FORBRUKERRADE, 2020).

Diversos países, portanto, reconhecem a vulnerabilidade agravada da criança, tal qual o ordenamento brasileiro, inclusive com disposições em parte similares. Refira-se que em âmbito internacional, em 2012, a Organização Mundial de Saúde emitiu as "Recomendações da Consulta de Especialistas da Organização Pan-Americana da Saúde sobre a Promoção e a Publicidade de Alimentos e Bebidas Não Alcoólicas para Crianças nas Américas” documento em que reconheceu os efeitos da publicidade de alimentos sobre preferências alimentares, comportamentos e saúde das crianças (à época, a televisão era o instrumento mais utilizado para transmissão da publicidade). A organização internacional defendeu a associação da publicidade à maior preferência por alimentos e bebidas com elevado teor de gordura, açúcar ou sal (ORGANIZAÇÃO PAN-AMERICANA DE SAÚDE, 2012, p. 3) - e isso incentivou 
diversos países a criarem normas voltadas à regulação da publicidade de alimentos não saudáveis. Vale destacar, também, a existência do "EU Pledge", uma iniciativa voluntária dos países da União Europeia, juntamente com empresas líderes da indústria de alimentos e bebidas, que visa mudar a forma como a publicidade é dirigida às crianças, com intuito de auxiliar os pais e responsáveis na adoção de dietas e estilos de vida saudáveis para seus filhos.

Em termos de América do Sul, na Colômbia, o artigo 12 da Lei $\mathrm{n}^{\circ}$ 1.355/09 determina que o Ministério da Proteção Social regulará, vigiará e controlará a publicidade de alimentos e bebidas para proteger a saúde da população, em especial da primeira infância e adolescência, com observância às determinações da Organização Mundial da Saúde. No Uruguai, o artigo 33 da "Ley de Meios" determina que as mensagens publicitárias não poderão produzir prejuízos morais ou físicos e que não devem incitar diretamente a compra de produtos/serviços, aproveitando-se da inexperiência e credulidade da criança. Não devem conter qualquer enganosidade, nem prometer prêmios ou recompensas com objetivo de atrair compradores, não podem ser apresentadas de forma que se aproveitem de sua lealdade e confiança, sobretudo com relação a seus pais e professores e não devem conter discriminação, nem menosprezar a dignidade humana. Inclusive, a norma proíbe o que denomina de "publicidade não-tradicional”, que seria o merchandising, em programas infantis. No Chile, um exemplo de país de vanguarda na área de proteção aos consumidores diante de alimentos ultraprocessados, em 2012 a Lei ${ }^{\circ} 20.606$ já determinava que a rotulagem dos alimentos deveria conter todos os seus ingredientes, incluindo os adicionados, em ordem decrescente de proporção $\left(\operatorname{art.} 2^{\circ}\right.$ ) e que a publicidade de alimentos não saudáveis não poderia ser dirigida a menores de 14 (quatorze) anos (art. $6^{\circ}$ ), além de não poder induzir para seu consumo. Inclusive, dentre as proibições, consta que a publicidade não poder ser veiculada durante concursos, jogos ou programas infantis. Em específico, em 2017, o Decreto $\mathrm{n}^{\circ} 24$ do citado país, determinou que quando o alimento superar os limites aceitáveis de sódio, açúcares e gorduras saturadas deve ficar proibida em todas as transmissões de cinema e televisão, das $6 \mathrm{~h}$ às $22 \mathrm{~h}$, a publicidade destinada a promover seu consumo. O Peru aprovou, em 2013, a Lei $\mathrm{n}^{\circ}$ 30.021, denominada Lei de Promoção de Alimentação Saudável para Crianças e Adolescentes. Visando o objetivo de promoção de saúde pública, de crescimento e desenvolvimento saudável das pessoas, determinou a regulação da publicidade (art. $1^{\circ}$ ) e estabeleceu, entre outras medidas, que a publicidade dirigida a menores de 16 (dezesseis) anos não poderá incentivar o consumo de alimentos ricos em gorduras trans, altos teores de açúcar, 
sódio e gorduras saturadas (art. $5^{\circ}$ ), além de impor a inserção de advertências como "Alto em" e "Contém gorduras trans. Evite seu consumo" (art. 10).

A publicidade tem sido um poderoso instrumento, no sentido de estimular hábitos alimentares pouco saudáveis, que primam pelo consumo de produtos ultraprocessados, em detrimento dos alimentos saudáveis. Essa realidade, especialmente quando a publicidade atinge crianças, afeta diretamente direitos fundamentais e direitos da personalidade - e o direito brasileiro não pode ficar alheio a essa temática.

\section{O CENÁRIO BRASILEIRO E OS ASPECTOS RELACIONADOS À PUBLICIDADE E AO CONSUMO DE ALIMENTOS ULTRAPROCESSADOS}

A Agência Nacional de Vigilância Sanitária, publicou em 09 de outubro de 2020, no Diário Oficial da União, a Resolução da Diretoria Colegiada - RDC n 429, de 8 de outubro de 2020, que instituiu normas sobre rotulagem nutricional de alimentos. A norma apresentou algumas novidades, dentre as quais destacam-se: a padronização de porções em 100 (cem) gramas para sólidos e semissólidos e 100 (cem) mililitros para líquidos (art. 8); a padronização de cores e tamanhos de letras (art. 16); a imposição de rotulagem nutricional frontal, com design de lupa, em alimentos cuja composição de nutrientes críticos (açúcares, gorduras e sódio) ultrapasse os limites estabelecidos pelo Anexo XV da Instrução Normativa $\mathrm{n}^{\circ}$ 75, de 2020 (art. 18, RDC n 429/2020). A Resolução buscou a efetivação do direito básico à informação do consumidor, consagrado pelo art. $6^{\circ}$, III, CDC. Vale rememorar que ao fornecedor incumbe o fornecimento de informação adequada e clara sobre as qualidades essenciais do produto/serviço, sendo que esse dever implica em direito, que compreende, ainda, alerta e aconselhamento para o consumidor, mediante informação sobre eventuais riscos que o produto possa apresentar. E reside neste ponto fulcral a problemática envolvendo os alimentos ultraprocessados que, reconhecidamente, representam um risco à saúde, conforme já demonstraram pesquisas científicas de qualidade.

De forma breve, crítica merece ser feita à redação contida na RDC n 429/2020, principalmente no diz respeito a certas flexibilizações que nela existem. Pode-se citar, por exemplo, a flexibilização de limite de nutrientes críticos e a ausência do adoçante como um desses nutrientes ${ }^{4}$. E mais, o design de lupa agora adotado no Brasil não é o modelo que

\footnotetext{
${ }^{4}$ Sobre o adoçante, destaca-se que seu consumo está associado a maiores riscos de obesidade, hipertensão, síndrome metabólica, diabetes tipo 2, acidente vascular cerebral e doenças cardiovasculares (AZAD, et al, 2-17). Ainda, a Sociedade Brasileira de Pediatria afirma que o consumo de adoçantes por crianças só faz sentido quando portadoras de diabetes e que a exposição a bebidas e alimentos adoçados pode alterar seu paladar (MANARINI, 2018).
} 
melhor informa o consumidor e por isso não foi o indicado pelo Instituto Brasileiro de Defesa do Consumidor, que defendeu a adoção do modelo de triângulos, mais eficientes para transmitir informação e servir como um alerta para elementos que nutrem pouco e colocam a saúde em risco (ANVISA, 2018, p. 58). Independente disso, mencione-se que a mens legis da resolução teve como escopo auxiliar na interpretação e, tanto quanto possível nesse modelo, simplificar as informações contidas na rotulagem nutricional, tudo com o propósito (eficaz ou não) de melhorar e facilitar o conhecimento por parte do consumidor sobre o conteúdo dos produtos alimentícios que consome. Apesar de serem justificadas as críticas de não ter sido adotado o melhor modelo, mesmo assim cabe salientar que a rotulagem nutricional frontal, busca informar o consumidor de maneira "célere" sobre a presença de nutrientes críticos nos alimentos.

Frente ao fato de seu preço normalmente ser mais acessível do que os de produtos mais saudáveis, seu hiperssabor (artificial) e a praticidade decorrente da facilidade de encontrá-los para compra, os alimentos ultraprocessados passaram a integrar a rotina alimentar do consumidor. Essa realidade se entendeu ao consumidor infantil (como exemplo, o consumo de biscoitos recheados, salgadinhos de pacote e refrigerantes, que as crianças muito apreciam), e a publicidade disso se aproveita. O resultado, porém, mostra que essas alterações nos padrões de nutrição guardam relação direta com o desenvolvimento de diversas doenças, como hipertensão arterial dislipidemia, diabetes mellitus tipo 2 e síndrome metabólica (DEPARTAMENTO DE NUTROLOGIA, 2019, p. 17). Dados do Sistema de Vigilância Nutricional e Alimentar (SISVAN) de 2015 apontam que das crianças de 5 (cinco) a 9 (nove) anos acompanhadas, 60\% consumiam biscoitos recheados, doces e guloseimas e $51 \%$ consumiam macarrão instantâneo, salgadinhos de pacote e biscoitos salgados. Ainda, entre as crianças de 0 (zero) a 5 (cinco) anos analisadas, 8,69\% estavam com peso elevado para a idade e entre as crianças de 5 (cinco) a 10 (dez) esse percentual aumentava para $11,95 \%$.

Em nível global, a obesidade entre crianças aumentou de 0,7\% em 1975 para 5,6\% em 2016 em meninas, e de 0,9\% em 1975 para 7/8\% em 2016 em meninos (EZATTI, 2017, p. 2637). No Brasil, o CENSO de 2010 apontou que em 2008 o excesso de peso atingia 33,5\% das crianças de 5 (cinco) a 9 (nove) anos; das crianças analisadas, 16,6\% dos meninos eram obesos e $11,8 \%$ das meninas eram obesas; o excesso de peso na área urbana era maior do que na área rural (37,5\% e 23,9\% dos meninos e 33,9\% e 24,6\% das meninas, respectivamente); entre as regiões, o Sudeste possuía a maior taxa de sobrepeso - 40,3\% dos meninos e $38 \%$ das 
meninas; em 1989, o percentual de meninos com excesso de peso era de $15 \%$ e em 1974/1975 chegava a 10,9\%, entre as meninas, o percentual em 1989 alcançava 11,9\% e em 1974/1975 alcançou 8,6\% (IBGE, 2010). Com base nessa realidade, o Guia Alimentar para a População Brasileira de 2014 (p. 39-43) recomendou que o consumo de alimentos ultraprocessados seja evitado, pois são nutricionalmente desbalanceados, o que significa dizer que são alimentos ricos em sódio, açúcares, gorduras e óleos e pobres em fibras, minerais e vitaminas. Portanto, o consumo de ultraprocessados está intimamente relacionado ao aumento do número de casos de sobrepeso e obesidade (ASKARI, et al, 2020), posto que estão associados à ingestão excessiva de calorias e tendem a limitar o consumo de alimentos in natura e de alimentos minimamente processados, melhores sob o ponto de vista nutricional.

Recentemente, a Nestlé, maior companhia mundial de alimentos, reconheceu que $70 \%$ dos produtos de seu portfólio não são saudáveis. Entre suas bebidas, esse percentual chega a 96\%, enquanto entre seus doces e sorvetes, chega a 99\%. A exemplo, o Nesquik em pó sabor morango, consumido com leite pelas crianças e definido como opção saborosa e nutritiva, que, em verdade, contém 14 (quatorze) gramas de açúcar em cada porção de 14 (quatorze) gramas do produto. Os dados coletados correspondem a produtos que totalizam metade das receitas anuais totais da Nestlé, valor equivalente a $\mathrm{R} \$ 533,38$ bilhões (EVANS, 2021). Ainda, estudos realizados pelo IDEC (2021) constataram a presença de resíduos de dezenas de agrotóxicos em alimentos ultraprocessados, a maioria destes com forte apelo ao público infantil. Um dos agrotóxicos encontrado foi o glifosato, herbicida mais vendido do mundo, cujas implicações para a saúde humana e para o meio ambiente ainda não estão bem definidas (FIOCRUZ, 2019). Aqui, ressalte-se, que por se tratar de gênero alimentício, os princípios da prevenção e da precaução deveriam ser aplicados, traduzindo a não tolerância ao risco, mesmo quando desconhecido, já que há exposição da saúde e da vida do consumidor, o que é motivo suficiente para que não sejam permitidas transigências, especialmente quando se trata do consumidor infantil.

Em que pese os esforços para conscientização sobre os nutrientes críticos dos alimentos através da imposição de rotulagem nutricional frontal, o fato é que quando se trata de alimentos destinados ao público infantil, a embalagem, a forma de rotulagem, a publicidade e até mesmo a disposição nas gôndolas dos estabelecimentos (como exemplo, cite-se que os produtos são dispostos em altura que permite a visualização e alcance pelas crianças) exercem grande influência para a compra, em detrimento da opção por alimentos mais saudáveis. Pesquisa produzida pela Universidade de Southampton demonstrou que a 
colocação de alimentos saudáveis, como frutas, verduras e água, em locais proeminentes, tende a influenciar os padrões de compra, reduzindo o consumo de doces e produtos de confeitaria. O estudo afirma a importância da expansão de regulamentações que determinem a colocação da seção de produtos de hortifrutigranjeiros mais próxima das entradas dos mercados, como forma de estímulo à aquisição desses produtos (VOGEL, et al, 2021). Pesquisa do IDEC e da UNICEF (2019), mostrou que a publicidade de produtos ultraprocessados acaba influindo na escolha de alimentos não-saudáveis e que a questão torna-se ainda mais problemática quando a veiculação se destina ao público infantil, pois seu estágio de desenvolvimento cognitivo e emocional impede que sejam capazes de se posicionarem criticamente e de realmente se autodeterminarem frente à publicidade abusiva (ou seja, na prática, têm seu direito de escolha condicionado/limitado).

Bruno Miragem (2019, p. 202) reitera que crianças desempenham importante papel nos hábitos de consumo dos adultos, detendo certo poder nas decisões de compra familiares, poder este que contrasta com sua hipervulnerabilidade frente às técnicas de marketing do mercado, costumeiramente sedutoras, posto que são mais influenciáveis e se deixam convencer com maior facilidade em função de sua formação intelectual incompleta, além de não saberem medir os riscos do negócio. Estudos do Imperial College of London apontam que crianças e adolescentes são mais suscetíveis ao marketing do que os adultos, o que demonstra a necessidade de reduzir sua exposição à divulgação de comidas obesogênicas, como forma de protegê-los dos riscos que o consumo de alimentos ultraprocessados pode causar (EZZATI, 2017, p. 2367). As comunicações sofisticadas de marketing estimulam o consumo de alimentos não saudáveis e a adoção de dietas de alta densidade energética e pobres em nutrientes, o que conduz ao ganho de peso, condição desencadeadora de várias patologias que prejudicam a saúde da pessoa (CAIRNS, et al, 2012, p. 13-16). Por isso, defende-se que deveria haver completa vedação quanto à inserção de personagens, cores e elementos lúdicos do universo infantil como forma de influenciar o consumo; e tal vedação deveria ser estendida para todo o mercado, incluindo as gôndolas e demais elementos dos estabelecimentos comerciais. E mais, impedir-se que, na Internet, os denominados influenciadores digitais divulguem qualquer tipo de produto, fazendo a criança se iludir ao crer que o consumo dele é gostoso, nutritivo e inofensivo à saúde.

No Brasil, em decisão histórica, o Superior Tribunal de Justiça, no julgamento do Recurso Especial n ${ }^{\circ} 1.558 .086 / \mathrm{SP}$, considerou duplamente abusiva a publicidade denominada de "É hora do Sherek". Primeiro, porque a peça publicitária era voltada diretamente ao 
público infantil. Segundo, porque condicionava a aquisição de um relógio à compra de 5 (cinco) produtos da linha "Gulosos Bauducco", caracterizando, portanto, uma venda casada. Em seu voto, afirmou o relator Ministro Humberto Martins que era abusivo o marketing de alimentos dirigido à criança e que a decisão de compra e consumo de gêneros alimentícios devia residir nos pais. O Ministro Herman Benjamin estava presente durante julgamento e afirmou em seu voto que o julgamento era histórico e servia para toda a indústria alimentícia. Ainda, defendeu que nenhuma empresa comercial tem direito constitucional ou legal assegurado de tolher a autoridade e o bom senso dos pais. No mesmo sentido, em 2018, o juiz Kenichi Koyama, do TJSP, julgou abusiva publicidade voltada ao público infantil, pois os brinquedos que nela constavam recebiam mais destaque do que o alimento e demais elementos, utilizando-se, portanto, de certa manipulação da deficiência de julgamento das crianças, como forma de convencê-las ao consumo, o que representava também, violação ao princípio da identificação publicitária (Processo $\mathrm{n}^{\circ}$ 1015328-03.2014.8.26.0053). Ressalte-se que só será lícita a publicidade quando o consumidor fácil e imediatamente a identifique como tal. Ao se referir a crianças, diante da falta de discernimento crítico e conhecimento destas, por obediência ao princípio da identificação, não há que se falar em publicidade lícita, pois o público infantil não possui discernimento para tal distinção. Reforça-se, portanto, a importância da regulação da publicidade, que influencia as escolhas alimentares das crianças. No caso dos alimentos ultraprocessados, a publicidade acaba por determinar o padrão de consumo e as preferências alimentares do público infantil, tudo com as já citadas decorrências para a saúde dos menores, ou seja, há afetação de direitos fundamentais e da personalidade destes. Portanto, a todos cabe contribuir para que seja incentivada a alimentação saudável, sendo que o mercado publicitário não pode ficar alheio a essas prescrições.

O ordenamento jurídico e os tribunais brasileiros vêm reconhecendo e punindo a abusividade das publicidades que têm como público-alvo a criança, em suas mais diversas formas, consoante se conclui dos julgados. A publicidade de alimentos, por envolver questões delicadas como a autoridade dos pais, alimentação, saúde e pleno desenvolvimento das crianças, merece especial cuidado. Ressalte-se que o ideal seria que a publicidade, já que tem o condão de incentivar o consumo, fosse colocada em alimentos saudáveis, para auxiliar na melhoria dos hábitos alimentares e estimular o consumo desse gênero alimentício (como os produtos in natura e os minimamente processados).

\section{PROTEÇÃO DA CRIANÇA CONTRA PUBLICIDADE ENQUANTO TUTELA DOS DIREITOS DA PERSONALIDADE E DOS DIREITOS FUNDAMENTAIS}


A determinação de que aos fornecedores incumbe o dever de informar aos consumidores possui três principais dimensões: a informação-conteúdo, a informaçãoadvertência e a informação-aconselhamento. A informação-conteúdo consiste na explicitação sobre as características, qualidade, composição nutricional do produto, etc. Neste caso, conforme já exposto, a forma de divulgar a informação seria mais adequada se o Brasil tivesse adotado o modelo de triângulos. Já a informação-advertência consiste no alerta para eventuais riscos que o produto pode causar e tal não tem sido exigido no nível desejado, seja em termos de legislação regulatória, seja em termos de fiscalização. Em complemento, encoberta sob o argumento de proteção da livre iniciativa, a informação-aconselhamento, que deveria orientar para que o consumidor optasse por hábitos mais saudáveis, bem como quanto a quantidade e frequência do consumo de alimentos ultraprocessados, não acontece no cenário brasileiro. Aliás, fornecedores consideram que tal representaria uma "contrapropaganda" (na verdade, uma contrapublicidade) a que não estão obrigados pela legislação - afinal, nenhuma empresa fornecedora de alimentos ultraprocessados admitiria em suas veiculações que o produto possui risco elevado em razão de seus altos teores de açúcares, gorduras e sódio. E mais: o fornecedor deveria providenciar informações alertando que os alimentos ultraprocessados podem prejudicar a saúde daqueles que os consomem de forma inadequada, mas que as crianças - seres em desenvolvimento - precisam de maior proteção. Possível afirmar, portanto, que ao Estado cabe a regulamentação e a regulação da publicidade que tem como público-alvo o público infantil, especialmente a que envolve alimentos ultraprocessados. E, ao fornecedor, enquanto particular, cabe o respeito aos direitos do consumidor, com aplicação da teoria da eficácia horizontal dos direitos fundamentais.

A escolha de dieta alimentar, que deveria ser livre e bem informada, ainda se revela aquém no cenário brasileiro, apesar do expresso no art. 196 da Constituição Federal, que determina que ao Estado incumbe o desenvolvimento de políticas sociais e econômicas que visem redução do risco de doenças e de outros agravos - a saúde é, sabidamente, um direito fundamental de segunda geração. Objetivamente, se está a tratar de um direito humano, fundamental e da personalidade, ainda mais se tratando de crianças (que devem ser protegidas até mesmo levando em consideração a responsabilidade intergeracional). O direito à saúde traduz respeito à segurança, à vida e à integridade físico-psíquica. E quando se trata de crianças a tutela adquire maior relevância, pois são seres em desenvolvimento, que merecem especial proteção, consubstanciada no princípio da dignidade da pessoa humana e no princípio 
da prioridade do melhor interesse da criança. Frise-se que os direitos da personalidade buscam, em sua essência, assegurar que a pessoa possa exercer livremente sua individualidade e são, portanto, essenciais ao seu pleno desenvolvimento. À criança são assegurados direitos fundamentais (mandamento constitucional do art. 227) e pleno desenvolvimento físico, mental, moral, espiritual e social, em condições de liberdade e de dignidade (art. $3^{\circ}$, Lei ${ }^{\circ}$ 8.069/90), cabendo à família, à comunidade, à sociedade em geral e ao poder público assegurar a efetivação de seus direitos. E a alimentação saudável nisso se inclui.

Não se procura afastar a responsabilidade dos pais e responsáveis de imporem a seus filhos dietas e estilos de vida saudáveis, mas se reconhece que ao Estado cabe a regulamentação e a regulação dos detalhes relacionados à fabricação e à comercialização dos produtos ultraprocessados, bem como da publicidade dirigida ao público infantil, hipervulnerável diante do mercado de consumo. Para que se efetive o direito à vida digna e com qualidade, a saúde é imprescindível, de modo que o direito não deve ser excessivamente tolerante a transigências que apenas favorecem o mercado. Ao fornecedor, por fim, cabe o dever ético, face a ausência de regulação rígida, de fornecer todas as informações substanciais ao consumidor sobre a composição exata de seus produtos, os riscos que apresentam e indicar que o alimento rico em nutrientes críticos não é o adequado à uma alimentação e vida saudáveis, além de não dirigir publicidade à criança, por carecer de senso crítico, experiência, maturidade e discernimento. Como já referido, a questão da ingestão de alimentos ultraprocessados envolve de direitos humanos, fundamentais e da personalidade das crianças.

\section{CONCLUSÃO}

Conforme demonstrado, os alimentos ultraprocessados estão associados ao excesso de peso, obesidade, diabetes, cardiopatias e outras doenças. Muito embora a RDC $\mathrm{n}^{\circ}$ 429/2020 tenha buscado efetivar a tutela do consumidor (prevista também no art. 5\%, XXXII, da $\mathrm{CF}$ e no art. $6^{\circ}$, III, do CDC), é importante consignar que a referida legislação está em parte aquém das exigências para ter-se um mercado, desde a publicidade até o pós-consumo, que, em prol de políticas públicas e da proteção individual, seja realmente direcionado/condicionado (como um nudge, um pequeno empurrão para o bem) para a proteção da saúde do consumidor. Tem-se um conjunto de fatores em que restou prejudicada, em grande parte, a tutela do consumidor - desde a falta de educação para o consumo (que é dever do fornecedor) para crianças e responsáveis por elas, até a ausência de limites mais rígidos para nutrientes críticos e a adoção do design de lupa, cuja eficácia é reduzida quando 
comparada com os demais modelos. Os atrativos utilizados pelas empresas que fabricam e/ou comercializam alimentos ultraprocessados prevaleceram sobre critérios mais rígidos para apresentação de embalagens, rotulagens e, sobretudo, da publicidade (importante vetor de convencimento para o consumo desses alimentos. Destaque-se que, especialmente no que refere à criança, deveria ser conferida impositividade ao $\$ 2^{\circ}$ do artigo 37 do $\mathrm{CDC}$, que elenca como abusiva a publicidade que se aproveita de sua deficiência de julgamento e experiência, e à Resolução no 163/2014 do CONANDA, que prescreve como abusivo o direcionamento da publicidade e da comunicação mercadológica ao público infantil. E nesse contexto é que o Poder Judiciário tem se posicionado, utilizando dos instrumentos conferidos pela legislação para ser possível alcançar justiça no caso concreto.

Assim, no tocante à influência para o consumo de alimentos ultraprocessados, as proteções inferem para a vida com qualidade. Se não for protegida a saúde do consumidor, em especial quanto as crianças (mercado preferencial para esses produtos), por evidente, direitos fundamentais restam e restarão abalados, pois as consequências se protraem no tempo, e, principalmente, refira-se, direitos da personalidade são colocados em risco de desrespeito (incluindo a integridade físico-psíquica e direito ao livre desenvolvimento). Reflita-se que interesses comerciais não podem sobrepujar a proteção do ser humano, razão e justificativa para existência do direito e de toda a ordem estatal.

\section{REFERÊNCIAS}

ALPA, Guido. Diritto privato dei consumi. Bolgna: Il Mulino, 1986.

ANVISA. Relatório Preliminar de Análise de Impacto Regulatório sobre Rotulagem Nutricional. 2018. Disponível em: <https://pesquisa.anvisa.gov.br/upload/surveys/981335/files/An\%C3\%A1lise\%20de\%20Impacto\%20Regulat\%C 3\%B3rio\%20sobre\%20Rotulagem\%20Nutricional.pdf>. Acesso em: 28 mar. 2021.

ASKARI, Mohammadreza; et al. Ultra-processd food and the risk of overweight and obesity: a systematic review and meta-analysis of observational studies. International jornal of obesity, 2020. Disponível em: https://www.nature.com/articles/s41366-020-00650-z. Acesso em: 30 abr. 2021.

AZAD, Meghan B.; et al. Nonnutritive sweetners and cardiometabolic health: a systematic review and metaanalysis of randomized controlled trials and prospective cohort studies. Canadian Medical Association Journal, 2017. Disponível em: <https://www.cmaj.ca/content/189/28/E929\#ref-7> Acesso em: 26 abr. 2021.

BRASIL. Guia alimentar para a população brasileira. Ministério da Saúde, 2014. Disponível em: <https://bvsms.saude.gov.br/bvs/publicacoes/guia_alimentar_populacao_brasileira_2ed.pdf>. Acesso em: 05 abr. 2021.

BRASIL. Superior Tribunal de Justiça. Recurso especial n ${ }^{\circ}$ 1.558.086/SP. Relator: Ministro Humberto Martins, 10 de março de 2016. Disponível em:

https://processo.stj.jus.br/processo/revista/documento/mediado/?componente=ITA\&sequencial=1495560\&num_ registro=201500615780\&data=20160415\&formato=PDF. Acesso em: 16 set. 2021 . 
BRASIL. Tribunal de Justiça do Estado de São Paulo. Processo n ${ }^{\circ}$ 1015328-03.2014.8.26.0053. Juiz Kenichi Koyama, 01 de abril de 2016. Disponível em:

https://esaj.tjsp.jus.br/cpopg/show.do?processo.codigo=1H0006JCF0000\&processo.foro=53\&processo.numero= 1015328-03.2014.8.26.0053\&uuidCaptcha=sajcaptcha_092dafb9c14244c69f6c621a2fd148f6. Acesso em: 30 jun. 2021.

BUNDESMINISTERIUM für familie, senioren, frauen und jugend. Jugendschutzgesetz und jugendmedienschutz-staatsvertrag der lander. Disponível em: https://criancaeconsumo.org.br/wpcontent/uploads/2014/06/Jugendschutzgesetz-Jugendmedienschutz-Staatsvertrag.pdf. Acesso em: 01 jul. 2021.

CAIRNS, G.; et al. Systematic reviews of the evidence on the nature, extent and effects of food marketing to children. A retrospective summary. Appetite, 2012. Disponível em:

https://core.ac.uk/reader/76980817?utm_source=linkout. Acesso em: 01 maio 2021.

CANADIAN. The canadian code of advertisign standards. Disponível em: https://adstandards.ca/code/thecode-online/. Acesso em 01 jul. 2021.

CAVAliERI FILHO, Sérgio. Programa de direito do consumidor. 4. ed. São Paulo: Atlas, 2014.

CHANG, Kiara; et al. Association Between Childhood Consumption of Ultraprocessed Food and Adiposity Trajectories in the Avon Longitudinal Study of Parents and Children Birth Cohort. JAMA Pediatrics, 2021. Disponível em: https://jamanetwork.com/journals/jamapediatrics/fullarticle/2780512. Acesso em: 22 set. 2021.

CHILE. Decreto ${ }^{\circ}$ 24, de 12 de julho de 2017. Disponível em:

https://www.bcn.cl/leychile/navegar?idNorma=1111356. Acesso em: 02 jul. 2021.

CHILE. Lei $\mathbf{n}^{\circ}$ 20.606, de 06 de julho de 2012. Disponível em:

https://www.bcn.cl/leychile/navegar?idNorma=1041570\&idVersion=2012-07-06. Acesso em: 02 jul. 2021.

COLOMBIA. Ley $\mathbf{n}^{\circ} 1355$ de 2009. Disponível em:

https://www.icbf.gov.co/cargues/avance/docs/ley_1355_2009.htm. Acesso em: 01 jul. 2021.

DENMARK. Marketing practices act. 2017. Disponível em:

https://www.consumerombudsman.dk/media/14553/markedsfoeringsloven-lbkg-2013.pdf. Acesso em: 01 jul. 2021.

DEPARTAMENTO de nutrologia. Manual de orientação. 3. ed. São Paulo: Sociedade Brasileira de Pediatria. 2019. Disponível em: 〈https://www.sbp.com.br/fileadmin/user_upload/Manual_de_Obesidade__3a_Ed_web_compressed.pdf $>$. Acesso em: 31 mar. 2021.

ENGLAND. Generic code of practice on television advertising standards. 2013. Disponível em: https://criancaeconsumo.org.br/wp-content/uploads/2014/06/code_tvad_e.pdf. Acesso em: 01 jul. 2021.

ESPAÑA. Ley $\mathbf{n}^{\circ}$ 34, de 11 de noviembre de 1988. Disponível em:

https://noticias.juridicas.com/base_datos/Admin/134-1988.t2.html\#a3. Acesso em: 01 jul. 2021.

EU PLEDGE. Disponível em: https://eu-pledge.eu/. Acesso em: 02 jul. 2021.

EVANS, Judith. Documento da Nestlé diz que a maior parte de seus alimentos não é saudável. Folha de São Paulo, 2021. Disponível em: https://www1.folha.uol.com.br/equilibrioesaude/2021/06/documento-da-nestle-dizque-a-maior-parte-de-seus-alimentos-nao-e-saudavel.shtml. Acesso em: 09 jun. 2021.

EZZATI, Majid, Worldwide trends in body-mass index, underweight, overweight, and obesity from 1975 to 2016: a pooled analysis of 2416 population-based measurement studies in 128.9 million children, adolescents, and adults. In: The Lancet, vol. 390, 2017. Disponível em:

https://www.thelancet.com/pdfs/journals/lancet/PIIS0140-6736(17)32129-3.pdf. Acesso em: 28 mar. 2021.

FIOCRUZ. Entenda o que é o glifosato, o agrotóxico mais vendido do mundo. 2019. Disponível em: https://cee.fiocruz.br/?q=node/987. Acesso em: 09 jun. 2021. 
FORBRUKERRADE. O Conselho do Consumidor alerta contra bombas de açúcar para bebês. 2020 . Disponível em: https://www.forbrukerradet.no/siste-nytt/forbrukerradet-advarer-mot-sukkerbomber-tilspedbarn/. Acesso em: 01 jul. 2021.

HERMAN BENJAMIN, Antônio de Vasconcellos. Práticas comerciais. In: GRINOVER, Ada Pellegrini, et al. Código brasileiro de defesa do consumidor comentado pelos autores do anteprojeto. Rio de Janeiro: Forense Universitária. 1991.

IBGE. POF 2008-2009. 2010. Disponível em: <https://censo2010.ibge.gov.br/noticiascenso?busca $=1 \& \mathrm{id}=1 \&$ idnoticia $=1699 \& \mathrm{t}=$ pof-20082009-desnutricao-cai-peso-criancas-brasileiras-ultrapassapadrao-internacional\&view=noticia>. Acesso em: 31 mar. 2021.

IDEC. Estudo inédito detecta agrotóxicos em alimentos ultraprocessados. 2021. Disponível em: https://idec.org.br/release/estudo-inedito-detecta-agrotoxicos-em-alimentos-ultraprocessados. Acesso em: 09 jun. 2021.

IDEC; UNICEF. Influência dos rótulos de alimentos ultraprocessados na percepção, preferências e escolhas alimentares de crianças brasileiras. IDEC, 2019. Disponível em:

<https://idec.org.br/sites/default/files/arquivos/pesquisa_idec_unicef_7.pdf>. Acesso em: 05 abr. 2021.

IRELAND. Advertising Standards Autorithy for Ireland. Disponível em: https://www.asai.ie/asaicode/children/. Acesso: em 01 jul. 2021.

MANARINI, Thaís. Em busca do adoçante perfeito. In: Saúde é vital, 2018. Disponível em: https://www.sbp.com.br/fileadmin/user_upload/Revista_Saude_agosto_de_2018_adocantes_dra._Virginia_Weff ort.pdf. Acesso em: 30 abr. 2021.

MIRAGEM, Bruno. Curso de direito do consumidor. 8. ed. São Paulo: Revista dos Tribunais, 2019.

ORGANIZAÇÃO PAN-AMERICANA DE SAÚDE. Recomendações da consulta de especialistas da organização pan-americana da saúde sobre a promoção e a publicidade de alimentos e bebidas não alcoólicas para crianças nas américas. 2012. Disponível em:

https://iris.paho.org/bitstream/handle/10665.2/3593/Experts_Food_Marketing_to_Children_\%28POR\%29.pdf?s equence=1\&isAllowed=y. Acesso em: 02 jul. 2021.

PERU. Ley $\mathbf{n}^{\circ}$ 30.021, de 01 de agosto de 2013. Disponível em:

https://siteal.iiep.unesco.org/sites/default/files/sit_accion_files/siteal_peru_0137.pdf. Acesso em: 02 jul. 2021.

PORTUGAL. Decreto- Lei no 330/90, de 23 de outubro de 1990. Disponível em:

http://www.bocc.ubi.pt/pag/estado-portugues-codigo-publicidade.html. Acesso em: 01 jul. 2021.

SISVAN. Relatório Público. SISVAN Relatórios, 2015. Disponível em:

https://sisaps.saude.gov.br/sisvan/relatoriopublico/consumoalimentar. Acesso em: 05 abr. 2021.

THE NETHERLANDS. The Dutch Advertising Code. Amsterdam, 2011. Disponível em:

https://criancaeconsumo.org.br/wp-content/uploads/2014/06/20110515_nrc_engels.pdf. Acesso em: 01 jul. 2021.

URUGUAY. Ley de Meios. Disponível em: http://www.diputados.gub.uy/wp-content/uploads/2013/12/0800C2607-13.pdf. Acesso em: 01 jul. 2021.

VOGEL, Christina; et al. Altering product placement to create a healthier layout in supermarkets: Outcomes on store sales, customer purchasing, and diet in a prospective matched controlled cluster study. In: Plos One, 2021. Disponível em: https://journals.plos.org/plosmedicine/article?id=10.1371/journal.pmed.1003729. Acesso em: 16 set. 2021. 